\title{
Sex-Specific Long-Term Trends in Length of Hospital Stay, Postmenstrual Age at Discharge, and Survival in Very Low Birth Weight Infants
}

\author{
Matthias Fröhlich ${ }^{a}$ Tatjana Tissen-Diabaté ${ }^{b}$ Christoph Bührer ${ }^{a}$ \\ Stephanie Roll ${ }^{b}$ \\ aDepartment of Neonatology, Charité - Universitätsmedizin Berlin, Berlin, Germany; ${ }^{\mathrm{b}}$ Institute for Social Medicine, \\ Epidemiology and Health Economics, Charité - Universitätsmedizin Berlin, Berlin, Germany
}

\section{Keywords}

Long-term trends · Very low birth weight infant · Length of hospital stay · Postmenstrual age at discharge · Survival · Retrospective cohort study

\begin{abstract}
Introduction: In very low birth weight $(<1,500 \mathrm{~g}$, VLBW) infants, morbidity and mortality have decreased substantially during the past decades, and both are known to be lower in girls than in boys. In this study, we assessed sex-specific changes over time in length of hospital stay (LOHS) and postmenstrual age at discharge (PAD), in addition to survival in VLBW infants. Methods: This is a single-center retrospective cohort analysis based on quality assurance data of VLBW infants born from 1978 to 2018. Estimation of sex-specific LOHS over time was based on infants discharged home from neonatal care or deceased. Estimation of sex-specific PAD over time was based on infants discharged home exclusively. Analysis of in-hospital survival was performed for all VLBW infants. Results: In 4,336 of 4,499 VLBW infants admitted from 1978 to 2018 with complete data (96.4\%), survival rates improved between 1978-1982 and 1993-1997 (70.8 vs. 88.3\%; hazard ratio (HR) $0.20,95 \%$ confidence interval 0.14 , 0.30 ) and remained stable thereafter. Boys had consistently higher mortality rates than girls (15 vs. 12\%, HR $1.23[1.05$,
\end{abstract}

1.45]). Nonsurviving boys died later compared to nonsurviving girls (adjusted mean survival time $23.0[18.0,27.9]$ vs. 20.7 [15.0, 26.3] days). LOHS and PAD assessed in 3,166 survivors displayed a continuous decrease over time (19781982 vs. 2013-2018: LOHS days $82.9[79.3,86.5]$ vs. 60.3 [58.4, 62.1] days); PAD $40.4(39.9,40.9)$ vs. $37.4[37.1,37.6]$ weeks). Girls had shorter LOHS than boys $(69.4[68.0,70.8]$ vs. 73.0 $[71.6,74.4]$ days) and were discharged with lower PAD (38.6 [38.4, 38.8] vs. 39.2 [39.0, 39.4] weeks). Discussion/Conclusions: $\mathrm{LOHS}$ and PAD decreased over the last 40 years, while survival rates improved. Male sex was associated with longer LOHS, higher PAD, and higher mortality rates.

\section{(c) 2021 The Author(s)}

Published by S. Karger AG, Basel

\section{Introduction}

Length of hospital stay (LOHS) is matter of concern to parents, physicians, and policy makers. The impact of increased rates of survival in preterm infants with very low birth weight $(<1,500 \mathrm{~g}$, VLBW $)[1,2]$ on LOHS and postmenstrual age at discharge (PAD) has rarely been investigated. LOHS of VLBW infants is not only influenced by

Charité - Universitätsmedizin Berlin is a corporate member of Freie Universität Berlin and Humboldt Universität zu Berlin.
(C) 2021 The Author(s)

Published by S. Karger AG, Basel

This is an Open Access article licensed under the Creative Commons Attribution-NonCommercial-4.0 International License (CC BY-NC) (http://www.karger.com/Services/OpenAccessLicense), applicable to the online version of the article only. Usage and distribution for commercial purposes requires written permission. 
Table 1. Baseline characteristics of all included VLBW infants admitted between 1978 and 2018 (in total and by 10-year epoch)

\begin{tabular}{|c|c|c|c|c|c|}
\hline & $\begin{array}{l}\text { All, } \\
n(\%)\end{array}$ & $\begin{array}{l}1978-1987, \\
n(\%)\end{array}$ & $\begin{array}{l}\text { 1988-1997, } \\
n(\%)\end{array}$ & $\begin{array}{l}1998-2007, \\
n(\%)\end{array}$ & $\begin{array}{l}2008-2018 \\
n(\%)\end{array}$ \\
\hline All & $4,336(100 \%)$ & $602(13.9 \%)$ & $725(16.7 \%)$ & $1,174(27.1 \%)$ & $1,835(42.3 \%)$ \\
\hline \multicolumn{6}{|l|}{ Sex } \\
\hline Female & $2,148(49.5 \%)$ & 297 (49.3\%) & $342(47.2 \%)$ & $600(51.1 \%)$ & $909(49.5 \%)$ \\
\hline Male & $2,188(50.5 \%)$ & $305(50.7 \%)$ & $383(52.8 \%)$ & $574(48.9 \%)$ & $926(50.5 \%)$ \\
\hline Singletons & $2,814(66.7 \%)$ & $464(77.1 \%)$ & $530(73.1 \%)$ & $793(67.5 \%)$ & $1,027(59.7 \%)$ \\
\hline \multicolumn{6}{|c|}{ Gestational age (completed weeks) } \\
\hline $22-27$ & $1,780(41.1 \%)$ & $120(19.9 \%)$ & $277(38.2 \%)$ & $575(49.0 \%)$ & $808(44.0 \%)$ \\
\hline $28-31$ & $1,907(44.0 \%)$ & $317(52.7 \%)$ & $331(45.7 \%)$ & $465(39.6 \%)$ & $794(43.3 \%)$ \\
\hline $32-34$ & $532(12.3 \%)$ & $126(20.9 \%)$ & $99(13.7 \%)$ & $123(10.5 \%)$ & $184(10.0 \%)$ \\
\hline $35-36$ & $94(2.2 \%)$ & $35(5.8 \%)$ & $15(2.1 \%)$ & $9(0.8 \%)$ & $35(1.9 \%)$ \\
\hline$\geq 37$ & $23(0.5 \%)$ & $4(0.7 \%)$ & $3(0.4 \%)$ & $2(0.2 \%)$ & $14(0.8 \%)$ \\
\hline Mean (SD) & $28(3)$ & $30(3)$ & $29(3)$ & $28(3)$ & $28(3)$ \\
\hline Median (IQR) & $28(26-30)$ & $30(28-32)$ & $29(26-31)$ & $28(26-30)$ & $28(26-30)$ \\
\hline \multicolumn{6}{|l|}{ Birth weight } \\
\hline$<750 \mathrm{~g}$ & $838(19.3 \%)$ & $42(7.0 \%)$ & $114(15.7 \%)$ & $248(21.1 \%)$ & $434(23.7 \%)$ \\
\hline $750-999 \mathrm{~g}$ & $1,054(24.3 \%)$ & $133(22.1 \%)$ & $170(23.4 \%)$ & $306(26.1 \%)$ & $445(24.3 \%)$ \\
\hline $1,000-1249 \mathrm{~g}$ & $1,056(24.4 \%)$ & $176(29.2 \%)$ & $187(25.8 \%)$ & $290(24.7 \%)$ & $403(22.0 \%)$ \\
\hline $1,250-1,499 \mathrm{~g}$ & $1,388(32.0 \%)$ & $251(41.7 \%)$ & $254(35.0 \%)$ & $330(28.1 \%)$ & $553(30.1 \%)$ \\
\hline Mean (SD) & $1,051(299)$ & $1,141(244)$ & $1,084(279)$ & $1,021(290)$ & $1,026(321)$ \\
\hline Median (IQR) & $1,076(820-1,310)$ & $1,170(980-1,350)$ & $1,120(875-1,330)$ & $1,040(785-1,270)$ & $1,040(777-1,310)$ \\
\hline SGA, $<10$ th percentile & $799(18.4 \%)$ & $156(25.9 \%)$ & $131(18.1 \%)$ & $179(15.2 \%)$ & $333(18.1 \%)$ \\
\hline LGA, $>90$ th percentile & $196(4.5)$ & $17(2.8)$ & $38(5.2)$ & $68(5.8)$ & $73(4.0)$ \\
\hline SDS, Mean (SD) & $-0.5(1.1)$ & $-0.8(1.1)$ & $-0.5(1.0)$ & $-0.3(1.0)$ & $-0.5(1.1)$ \\
\hline
\end{tabular}

SD, standard deviation; IQR, interquartile range; SGA, small for gestational age; LGA, large for gestational age; SDS, standard deviation score; VLBW, very low birth weight.

biological factors and medical treatment $[3,4]$ but possibly also by financial incentives [5]. A recent study from the USA revealed in an overall increase in weight and PAD over the last decade [5] in spite decreased LOHS and PAD in infants born at less than 28-week gestation from 1993 to 2021 (42 vs. 37 weeks) [6].

Mounting evidence suggests risk for mortality [7-9] and morbidity [10-13] are higher in preterm boys, as opposed to girls [14]. Preterm boys and girls respond differentially to medication administered to treat or prevent intraventricular hemorrhage or bronchopulmonary dysplasia [15]. The aim of this study was to assess sex-specific long-term trends of LOHS, PAD, and survival to discharge in VLBW infants over a time period of 40 years.

\section{Methods}

\section{Study Design}

This is a retrospective cohort study using routine data of all VBLW infants collected for quality improvement purposes from the Children's Hospital of the Freie Universität Berlin (1978-1995) and the Charité - Universitätsmedizin Berlin (1996-2018). The data for the German perinatal survey are transferred to a central institute via a standardized data collection form that contains medical and socioeconomical items usually extracted from the final medical report of the infant. Since collecting institutes and variables have changed over time, only selected variables could be used for the present analysis. However, the data were almost complete as the legal mandate to collect data was present. Different rates of early death in earlier years as compared to recent years led to small risk sets among very preterm infants in early years (left truncation). Therefore, infants were excluded with a gestational age (GA) below 22 weeks, as were readmissions, or if there was missing data on sex, state of discharge, GA, LOHS, or source data. As multiples in the same pregnancy have virtually always the same GA and often are discharged together, analysis was adjusted for multiple status. For LOHS and PAD analysis, only infants who were discharged home from neonatal care were considered. For survival analysis, data on all infants discharged home or transferred were used. For the survival analysis, data were left truncated with the consequence of early small risk sets. In the analysis, we used the lower bound of 22-week gestation. Furthermore, in a sensitivity analysis, we used a survival model with postmenstrual age as the time scale to account for this problem. To investigate the effect of variation in methodology, we also performed logistic regression on mortality. 


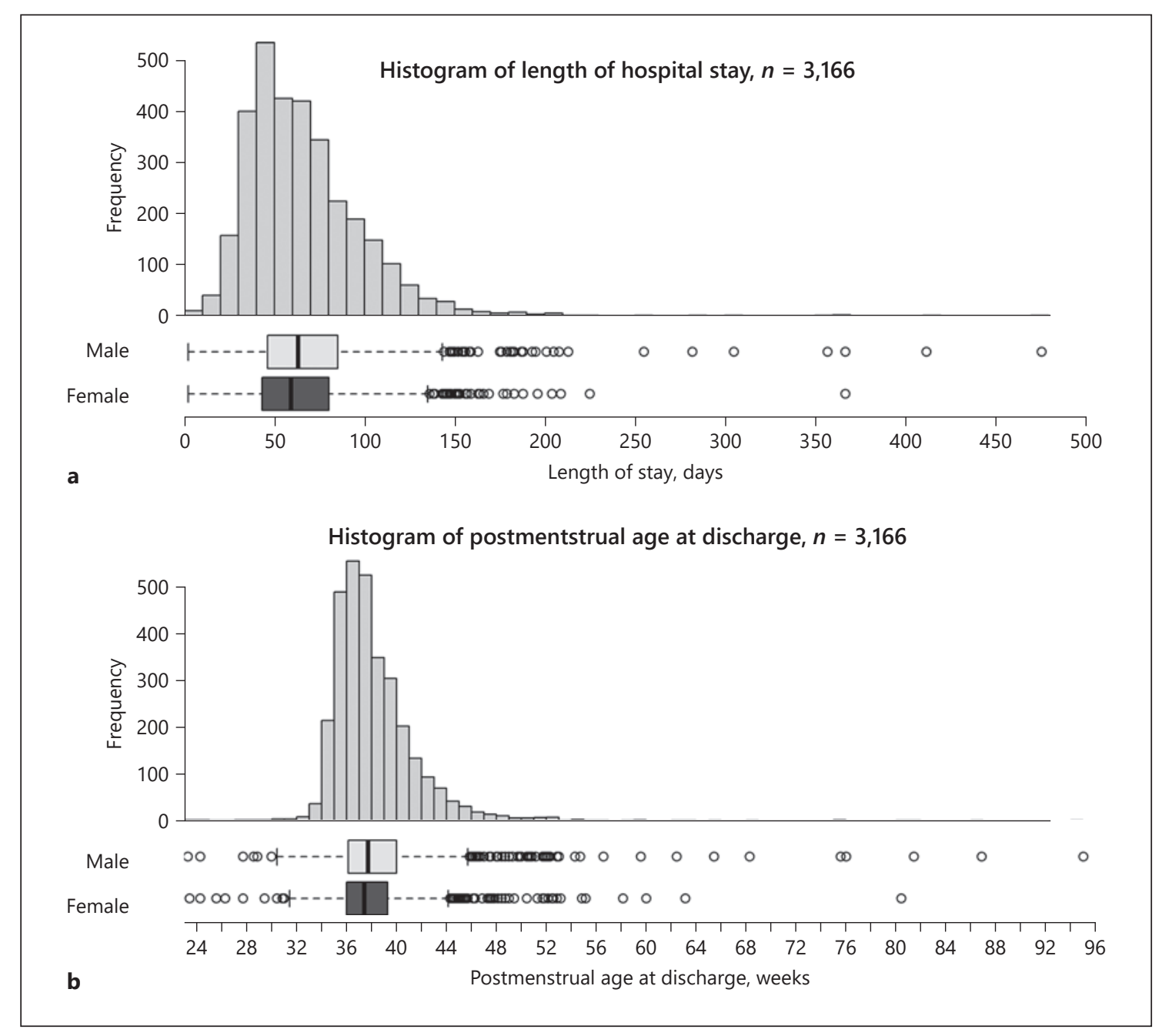

Fig. 1. LOHS (days, a) and PAD (completed weeks, b) by sex of 3,166 surviving VLBW infants discharged home (histogram and boxplots). VLBW, very low birth weight; LOHS, length of hospital stay; PAD, postmenstrual age at discharge.

\section{Definitions and Outcomes}

Sex was defined as the biological sex as documented by the treating physician. Small for GA (SGA) and large for GA (LGA) were defined as a weight below the tenth percentile, or above the ninetieth percentile for the GA according to German norm percentiles [16], respectively. The main outcome measure was the number of days from birth until discharge or death. GA was defined according to current clinical practice as the time span between the first day of the woman's last menstrual cycle to the date of birth (usually given as completed weeks and additional days). As GA was based on the best available obstetrical estimate, it was presumably less accurate during early years when early ultrasound measurements were available routinely. Since additional days were not documented consistently (especially not in the early years), days were set to zero, using only completed weeks. PAD was computed as the GA plus the time span in weeks between the date of birth and date of discharge or death. Mortality was defined as infant's death occurring prior to discharge from the hospital.
Discharge of a VLBW infant required the infant to be in a stable condition, being able to maintain body temperature without an exogenous heat source, drinking and eating full meals without need for gavage feeding, and absence of episodes of desaturation and bradycardia [17]. These rules were not fixed in writing but were established routines that had never been subjected to deliberate change.

\section{Statistical Analysis}

Descriptive statistics of infant characteristics were computed for all infants. For infant's birth weight, we also computed standardized values (standard deviation scores) using German reference values for birth weight [16]. Analysis of covariance was used for the outcomes LOHS and PAD, with the independent variables infant's sex and birth year (epoch). The models included the factor multiple status, interaction between sex and birth year, and, for analysis of LOHS, also the covariates GA at birth. Means with the respective $95 \%$ confidence intervals (CIs) for LOHS were computed adjusted for multiple status and GA, while PAD was adjusted for 
Table 2. LOHS (days, adjusted mean with 95\% CI) and PAD (completed weeks, adjusted mean with 95\% CI) of 3,166 VLBW infants discharged home and 611 VLBW infants who died

\begin{tabular}{|c|c|c|c|}
\hline & \multicolumn{2}{|l|}{ Discharged alive } & \multirow{2}{*}{$\begin{array}{l}\text { Nonsurvivors } \\
\text { length of stay, days } \\
\text { adjusted mean }(95 \% \mathrm{CI})^{1}\end{array}$} \\
\hline & $\begin{array}{l}\text { length of stay, days } \\
\text { adjusted mean }(95 \% \mathrm{CI})^{1}\end{array}$ & $\begin{array}{l}\text { PAD, weeks } \\
\text { adjusted mean }(95 \% \mathrm{CI})^{2}\end{array}$ & \\
\hline \multicolumn{4}{|l|}{ Sex } \\
\hline Female & $68.8(67.4-70.2)$ & $38.5(38.3-38.7)$ & $20.7(15.0-26.3)$ \\
\hline Male & $73.8(72.3-75.2)$ & $39.3(39.0-39.5)$ & $23.0(18.0-27.9)$ \\
\hline \multicolumn{4}{|l|}{ Year of birth } \\
\hline 1978-1982 & $83.2(79.6-86.8)$ & $40.5(40.0-41.0)$ & $20.8(11.1-30.5)$ \\
\hline 1983-1987 & $87.0(83.4-90.6)$ & $41.0(40.5-41.6)$ & $21.9(12.5-31.2)$ \\
\hline $1988-1992$ & $79.8(76.6-82.9)$ & $40.1(39.6-40.5)$ & $19.4(9.7-29.1)$ \\
\hline 1993-1997 & $73.7(70.6-76.9)$ & $39.3(38.8-39.7)$ & $13.2(0.2-26.1)$ \\
\hline 1998-2002 & $66.2(63.7-68.7)$ & $38.2(37.9-38.6)$ & $19.0(6.4-31.5)$ \\
\hline 2003-2007 & $57.9(55.6-60.2)$ & $37.1(36.7-37.4)$ & $37.6(28.4-46.8)$ \\
\hline 2008-2012 & $62.3(60.3-64.3)$ & 37.7 (37.4-37.9) & $25.2(15.0-35.4)$ \\
\hline 2013-2018 & $60.2(58.3-62.1)$ & $37.4(37.1-37.6)$ & $17.5(9.1-25.9)$ \\
\hline
\end{tabular}

VLBW, very low birth weight; PAD, postmenstrual age at discharge; GA, gestational age; CI, confidence interval. ${ }^{1}$ Adjusted for multiple status, GA at birth, and interaction between sex and birth year. ${ }^{2}$ Adjusted for multiple status and interaction between sex and birth year.

multiple status only. Birth year was included either numerically or in 5- or 10-year intervals (i.e., 4 or 8 epochs). In addition, we performed a sensitivity analysis of LOHS and PAD adjusting for SGA status. Survival rates were estimated with the cumulative incidence function for 100 days LOHS in addition to simple proportions. In addition, Cox proportional hazards regression on LOHS in days adjusting for GA at birth were performed to model differences in infant survival over 40 years and in sex. Due to left truncation, a sensitivity analysis was performed with postmenstrual age used as the time variable applied to the counting process formulation of proportional hazards. Because of small risk sets, for very preterm infants below 23-week gestation in early epochs, we used 24-week gestation as lower bound for this analysis. Hazard ratios (HR) for birth year and infants' sex were estimated (with 95\% CI). Furthermore, survival rates were analyzed with multiple logistic regression to assess the sensitivity of the results. All results were considered explorative with no formal level of significance and no adjustment for multiple testing. Analysis was performed in R (version 3.6) with the packages etm, survminer, and emmeans [18]. Ethical approval was obtained by the institutional review board of the Charite - Universitätsmedizin Berlin (EA2/212/19) and informed consent was not necessary for this retrospective analysis.

\section{Results}

\section{Study Cohort}

Between 1978 and 2018, a total of 4,499 VLBW infants were admitted to the department of neonatology. We excluded infants who were born with GA $<22$ weeks' gesta- tion $(n=6)$, readmissions $(n=9)$, or cases with missing data for sex $(n=6)$, state of discharge $(n=16)$, GA $(n=34)$, LOHS $(n=86)$, or source data $(n=6)$, leaving $4,336(96.4 \%)$ cases as shown in online supplementary Figure 1; (see www. karger.com/doi/10.1159/000515899 for all online suppl. material). Among this cohort, 799 (18.4\%) infants were SGA and 196 (4.5\%) were LGA with an increase of SGA after the first decade. In addition, the proportion of very preterm infants with extremely low birth weight increased over time, as shown in Table 1. For the analysis of LOHS, we included only infants who were discharged home from neonatal care $(n=3,243)$ with 77 infants excluded due to missing multiples status, resulting in $n=3,166$ infants. The absolute number of VLBW infants per year increased over time $(N=4,336 ; 1978: n=62$ [1.4\%]; 2018: $n=177$ [4.1\%]), while sexes were equally distributed (female $n=2,148$ [49.5\%]). The proportion of singleton versus multiple gestation pregnancies was 66.7 versus $33.3 \%$ with an increase of multiple pregnancies over time. The clinical characteristics in total and by epoch are presented in Table 1, characteristics by state of discharge in online suppl. Table 1.

\section{Length of Hospital Stay and Postmenstrual Age at Discharge}

For LOHS, we evaluated differences between male and female survivors over time, adjusting for the possible confounder multiplicity, GA at birth, as well as the interac- 


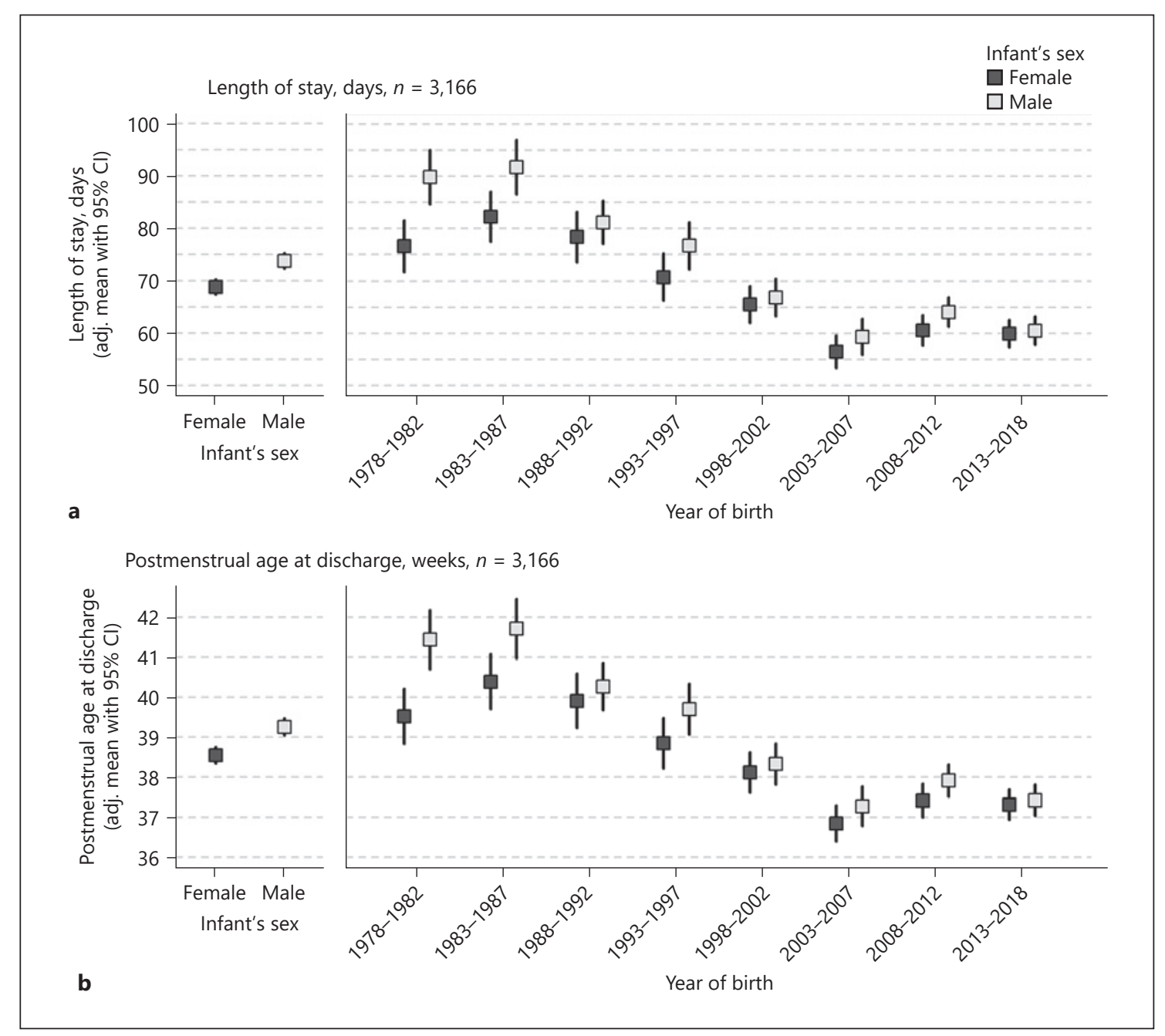

Fig. 2. LOHS (adjusted mean days, a) and PAD (adjusted mean completed weeks, b) by sex and birth year. LOHS model included the factor multiple status, GA at birth, and SGA status; PAD model included only multiple status. LOHS, length of hospital stay; PAD, postmenstrual age at discharge; GA, gestational age; SGA, small for gestational age; $\mathrm{CI}$, confidence interval.

tion of sex and time (birth year). The distribution of LOHS was right-skewed mean 66.9 days (SD 33.6), median of 61 (interquartile range $82-44=38$ ) . Figure 1a presents the distribution of LOHS by sex. Comparing sexes, we saw an overall difference of about 5 days between female and male infants in LOHS, with an adjusted mean LOHS of 68.8 days $(95 \%$ CI $67.4,70.2)$ for females and 73.8 days $(72.3,75.2)$ for males (Table 2$)$. There was a convergence in the LOHS between sexes over time, with the estimates becoming additionally more precise over time due to an increasing number of cases (Fig. 2a). LOHS decreased between the time intervals 1983-1987 to 20032007 (adjusted means 87.0 [83.4, 90.6] days vs. 57.9 [55.6, 60.2] days), increased slightly after 2007 , and stabilized through 2018 (60.2 [58.3, 62.1] days). Sensitivity analyses revealed the same pattern of LOHS and PAD between sexes as well as over time with slightly longer LOHS and higher PAD when adjusting for SGA status.

In addition, we analyzed the LOHS of nonsurvivors (Table 2, online suppl. Fig. 2): we saw a slightly longer time until death in nonsurviving boys as opposed to girls $(23.0[18.0,27.9]$ vs. $20.7[15.0,26.3]$ days $)$ and a changing pattern over time with a minimum of $13.2(0.2,26.1)$ days in 1993-1997 to a maximum of $37.6(28.4,46.8)$ days in 2003-2007 (Table 2).

For PAD, we assessed associations with infant's sex and birth year, adjusting for multiple status as well as the interaction of sex and birth year (Table 2). PAD was normally 


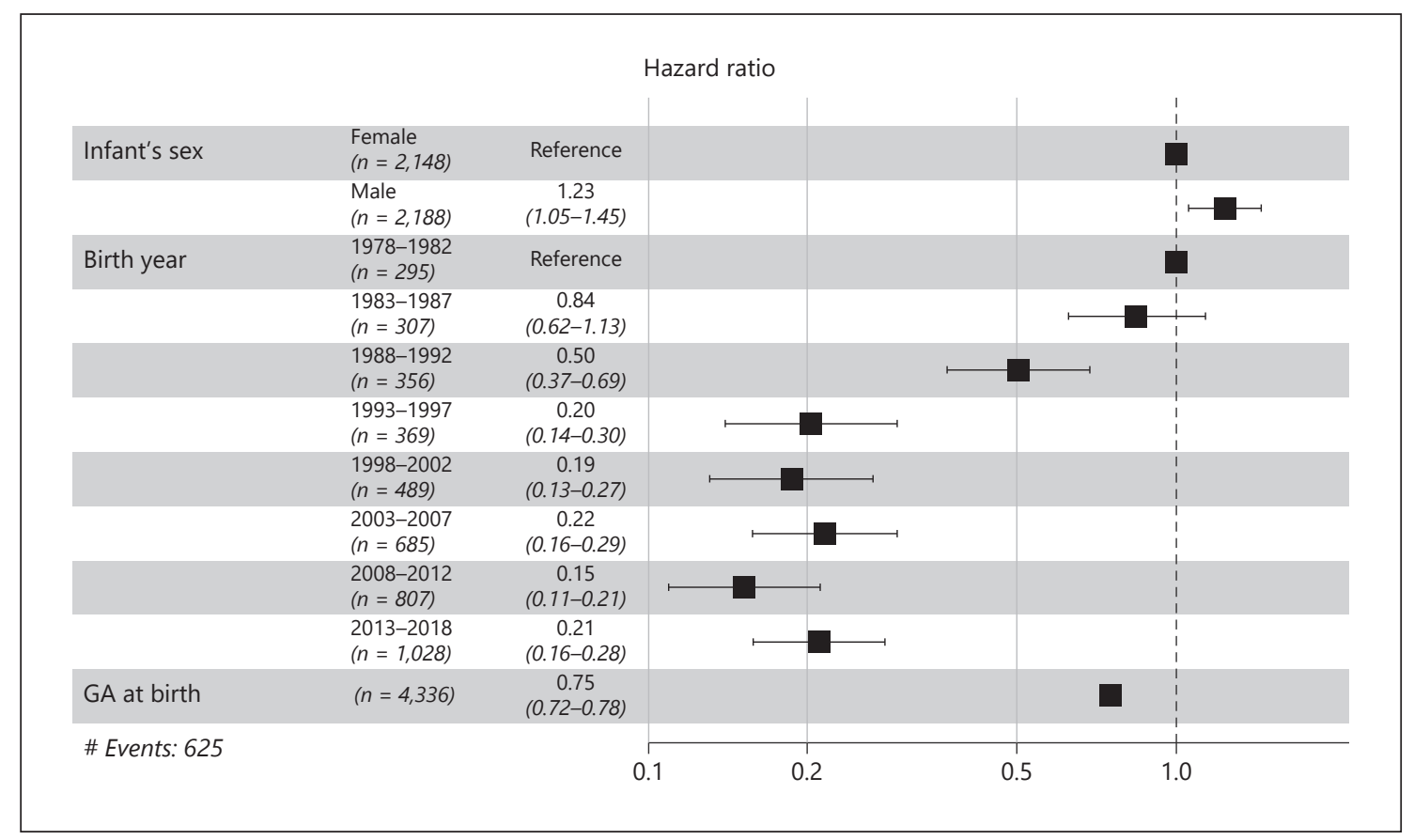

Fig. 3. Survival by sex and birth year, adjusted for GA of 4,336 VLBW infants (Cox proportional hazards analysis). VLBW, very low birth weight; GA, gestational age; HR, hazard ratio.

Table 3. Mortality incidence (\%) and survival (HR), adjusted for GA at birth $(N=4,336)$

\begin{tabular}{|c|c|c|c|c|c|}
\hline & $N$ & $\begin{array}{l}\text { Death, } \\
N(\%)\end{array}$ & $\begin{array}{l}100 \text { days cumulative } \\
\text { incidence of death before } \\
\text { discharge, } \%(95 \% \mathrm{CI})\end{array}$ & $\begin{array}{l}\text { Adjusted HR } \\
(95 \% \mathrm{CI})\end{array}$ & $\begin{array}{l}\text { Adjusted odds ratio } \\
(95 \% \mathrm{CI})\end{array}$ \\
\hline Female & 2,148 & $275(12.8)$ & $12.2(10.8,13.6)$ & Reference & Reference \\
\hline Male & 2,188 & $350(16.0)$ & $15.2(13.7,16.7)$ & $1.23(1.05,1.45)$ & $1.33(1.11,1.59)$ \\
\hline \multicolumn{6}{|l|}{ Year of birth } \\
\hline $1983-1987$ & 307 & $88(28.7)$ & $26.4(21.8,31.7)$ & $0.84(0.62,1.13)$ & $0.85(0.58,1.23)$ \\
\hline 1988-1992 & 356 & $79(22.2)$ & $21.1(17.2,25.7)$ & $0.50(0.37,0.69)$ & $0.45(0.30,0.65)$ \\
\hline 1993-1997 & 369 & $43(11.7)$ & $11.4(8.5,15.1)$ & $0.20(0.14,0.30)$ & $0.16(0.10,0.25)$ \\
\hline 1998-2002 & 489 & $51(10.4)$ & $10.2(7.8,13.3)$ & $0.19(0.13,0.27)$ & $0.13(0.09,0.20)$ \\
\hline $2003-2007$ & 685 & $86(12.6)$ & $11.7(9.5,14.3)$ & $0.22(0.16,0.29)$ & $0.14(0.10,0.21)$ \\
\hline $2008-2012$ & 807 & $69(8.6)$ & $8.2(6.5,10.3)$ & $0.15(0.11,0.21)$ & $0.10(0.06,0.14)$ \\
\hline
\end{tabular}

In addition, results from sensitivity analysis using logistic regression (odds ratio) adjusted for GA at birth. GA, gestational age; CI, confidence interval; HR, hazard ratio.

distributed to some extent (mean 38.3 weeks [SD 3.9], median 37.6 weeks [interquartile range 39.6-36.1 = 3.4]), and right-skewed as shown in Figure 1b. Regarding PAD, we observed a minor difference between males (adjusted mean $39.3[39.0,39.5])$ and females (38.5 weeks [38.3, 38.7]) with the same pattern of decreasing differences over time. After a slight increase from 1978-1982 to 1983-1987 to a mean PAD of $41.0(40.5,41.6)$, a decrease was observed until the years 2003-2007 with a minimum of 37.1 (36.7, 37.4)-week gestation, stabilizing at a mean PAD of 37.4 $(37.1,37.6)$ through 2018 as presented in Figure 2b. The results of LOHS and PAD analysis are presented in Table 2. 


\section{Survival}

In total, 625 infants (14.4\%) died before discharge. Among these, $48 \%$ survived less than 1 week. Based on LOHS data from all 4,336 cases, mortality rates were higher in males than in females (100 days cumulative incidence $15.2 \%$ [13.7, 16.7] vs. $12.2 \%[10.8,13.6])$. Over time, mortality rates decreased, from $27.5 \%(22.7,32.9)$ in $1978-1982$ to $11.5 \%(9.7,13.6)$ in $2013-2018$. The difference between sexes decreased over time (Table 3 ).

In a Cox proportional hazards regression, both infant's sex and birth year epoch were associated with survival (Fig. 3). Male infants showed a higher risk for mortality (HR $1.23[1.05,1.45])$. Survival improved substantially from 1978-1982 to $1993-1997$ (HR $0.20[0.14,0.30]$ ) and remained stable thereafter. The proportional hazards assumption was not met for all variables in the model. However, results from the logistic regression (sensitivity analysis) were similar (Table 3 ).

In another sensitivity analysis, results from logistic regression and Cox proportional hazard regression analysis for PAD were similar. Because of left truncation and small risk sets, mortality rates were generally higher in this sensitivity analysis (online suppl. Table 3).

\section{Discussion}

This retrospective cohort study, using routine data of more than 4,000 VLBW infants, demonstrates a decrease in LOHS, PAD, and mortality rates over the last 40 years. Male sex was a risk factor for longer LOHS, higher PAD, and lower survival over time.

\section{Sex Differences}

The sex difference in LOHS and survival is in line with a large body of evidence showing that boys are more likely to develop critical conditions and therefore require longer LOHS with lower rates of survival $[10-12,14]$. A systematic review of 26 studies reported worse male mortality outcome compared to girls [8], while 6 included studies and a population-based study from the Korea found no difference between sexes. In a sample of 1,08,038 mixed-gender twin pairs, there was no difference in fetal mortality but a significantly higher neonatal and infant mortality in males $[7,19]$. A study from Canada analyzing neonatal sex-specific outcomes showed a narrowing in the gap between sexes concerning mortality over time, a finding reproducible within our dataset [9].

The well-known differences between girls and boys may cause an implicit bias, as nurses and physicians may assume readiness for discharge earlier in girls than in boys. The difference between girls and boys of approximately 5 days might be of minor importance in relation to a mean LOHS of around 70 days. The same applies to the difference in the LOHS of the deceased children, which also allows for a very vague estimate due to the limited number of infants.

\section{Changes over Time}

Implementation of intensive neonatal care of preterm infants originating in the 1970s led to an increase in the number of infants requiring long-term hospital care and improved survival among this cohort. During the same time, medical progress such as antenatal steroids [20], exogenous surfactant replacement [21], and the professionalization of neonatology contributed to the decline in LOHS and the increase of survival in VLBW infants. Though decisive innovations of modern neonatology occurred within the past 2 decades, especially regarding survival, the effects of these achievements remained moderate. A study focusing on the 90s shows that the main progress during this period can be narrowed down to the first half of the decade up to 1995 and that further improvements are hardly visible after that [22]. This is in line with other studies reporting only minor changes in mortality since $2000[9,23,24]$.

Studies evaluating very preterm infants of 22- or 23week gestation revealed a mean LOHS of 150 days for 22-week infants and 144 days for 23-week infants [25]. Babies born at 30-31 weeks of gestation usually leave hospital around 1 month before due term [4]. Further reduction of LOHS may be achieved by family integrated care [26], skin-to-skin care [27], special feeding regimens [3], or prophylactic probiotics [28]. However, there are physiological barriers to discharge prior to 34 weeks PMA.

Recent reports of changes in LOHS from the USA show an increasing trend in PAD from 2005 to 2018 for infants born at 24- to 29 weeks' gestation. The authors suspect financial incentives as part of the cause of this development [5], as longer stay translates into increased remuneration in the USA. In contrast, a diagnose-related group system was introduced in Germany intended to curb the spending on hospitals in 2000. This was associated with a change in incentives from rewarding extended LOHS to rewarding diagnosis-specific LOHS and timely discharge. This may have contributed to the nadir of LOHS 2003-2007 observed in this study. There was little change thereafter, pointing to natural limits to discharge preterm infants safely, such as apneas, temperature insta- 
bility, and poor feeding. The overall mean LOHS in our study is in line with other clinical trials reporting LOHS as an outcome variable $[29,30]$.

\section{Strengths and Limitations}

Data of the German Federal Office of Statistics report on 6579 VLBW infants born between 1990 and 2010 in the city of Berlin, of whom 2,163 (32.9\%) were represented in our database. Since the 1980s, there has been a worldwide increase in the proportion of twins and higher order multiples, which is consistent with our findings [31-33]. While the extended observation period and the low percentage of missing values are major strengths of this analysis, they are derived from a single hospital. Therefore, it is difficult to assess external validity, and there might be local exceptions, but overall, we assume the observed trends to be generalizable. The limited list of items collected for the mandatory quality assurance offers little possibilities to adjust for other confounders that might have changed over the years including chronic conditions, social support, or other potential influencing factors. However, there is no reason to assume these factors to be systematically different between female and male infants, and are therefore not expected to confound the results. Since these factors might have changed within the last 4 decades, they possibly contribute to changes over time. The design of the study presented does not allow to investigate the independent contribution of all potentially influencing factors. No information can be provided about deaths before admission to neonatal care, and only infants who had been discharged home from neonatal care were included in LOHS analysis, while infants who were discharged from other hospitals or died after transfer were not taken into account [34]. The database was not linked to follow-up data which would have been useful to evaluate associations between duration of hospital stay and patient relevant outcome parameters such a neurodevelopmental impairment or learning disabilities.

\section{Conclusions}

This study shows that in VLBW infants, male sex and early decades are consistent risk factors for higher LOHS, $\mathrm{PAD}$, and mortality. All 3 variables decreased equally in both sexes over the last 4 decades, with the most prominent decline associated with the widespread introduction of antenatal steroids and postnatal surfactant replacement during the early 1990s. Further research should include possible consequences of early discharge regimes, such as readmissions or adverse events at home.

\section{Statement of Ethics}

Ethical approval was obtained by the institutional review board of the Charité - Universitätsmedizin Berlin (EA2/212/19) and informed consent was not necessary for this retrospective analysis.

\section{Conflict of Interest Statement}

The authors have no conflicts of interest to declare.

\section{Funding Sources}

This research received no specific grant from any funding agency in the public, commercial, or not-for-profit sectors.

\section{Author Contributions}

All authors approved the manuscript for publication and are accountable for the data contained therein. M.F. conceptualized and designed the study, drafted the research ethics application and the initial manuscript, and reviewed and revised the manuscript. T.T.D. conducted the initial analysis and reviewed and revised the manuscript. C.B. reviewed the initial study proposal and research ethics application, contributed to the acquisition, analysis and interpretation of data, and reviewed and revised the manuscript. All authors approved the final manuscript as submitted and agreed to be accountable for all aspects of the work. S.R. supervised the conceptualization and design of the study, contributed to the interpretation of data, and reviewed and revised the manuscript.

\section{References}

Sex-Specific Secular Trends in LOHS and Survival in VLBW
1 Field DJ, Dorling JS, Manktelow BN, Draper ES. Survival of extremely premature babies in a geographically defined population: prospective cohort study of 1994-9 compared with 2000-5. BMJ. 2008 May 31;336(7655):1221-3.

2 Seaton SE, Barker L, Jenkins D, Draper ES, Abrams KR, Manktelow BN. What factors predict length of stay in a neonatal unit: a systematic review. BMJ Open. 2016 Oct 18;6(10): e010466.
3 Hair AB, Bergner EM, Lee ML, Moreira AG, Hawthorne KM, Rechtman DJ, et al. Premature infants $750-1,250 \mathrm{~g}$ birth weight supplemented with a novel human milk-derived cream are discharged sooner. Breastfeed Med. 2016 Apr;11(3):133-7.

4 Seaton SE, Barker L, Draper ES, Abrams KR, Modi N, Manktelow BN, et al. Estimating neonatal length of stay for babies born very preterm. Arch Dis Child Fetal Neonatal Ed. 2019 Mar;104(2):F182-F86. 
5 Edwards EM, Greenberg LT, Ehret DEY, Lorch SA, Horbar JD. Discharge age and weight for very preterm infants: 2005-2018. Pediatrics. 2021 Feb;147(2):e2020016006.

6 Stoll BJ, Hansen NI, Bell EF, Walsh MC, Carlo WA, Shankaran S, et al. Trends in care practices, morbidity, and mortality of extremely preterm neonates, 1993-2012. JAMA. 2015 Sep 8;314(10):1039-51.

7 Shim SY, Cho SJ, Kong KA, Park EA. Gestational age-specific sex difference in mortality and morbidities of preterm infants: a nationwide study. Sci Rep. 2017 Jul 21;7(1):6161.

8 Vu HD, Dickinson C, Kandasamy Y. Sex difference in mortality for premature and low birth weight neonates: a systematic review. Am J Perinatol. 2018 Jul;35(8):707-15.

9 Garfinkle J, Yoon EW, Alvaro R, Nwaesei C, Claveau M, Lee SK, et al. Trends in sex-specific differences in outcomes in extreme preterms: progress or natural barriers? Arch Dis Child Fetal Neonatal Ed. 2020 Mar;105(2): 158-63.

10 Darlow BA, Hutchinson JL, HendersonSmart DJ, Donoghue DA, Simpson JM, Evans NJ. Prenatal risk factors for severe retinopathy of prematurity among very preterm infants of the Australian and New Zealand Neonatal Network. Pediatrics. 2005 Apr;115(4): 990-6.

11 Tioseco JA, Aly H, Essers J, Patel K, El-Mohandes AA. Male sex and intraventricular hemorrhage. Pediatr Crit Care Med. 2006 Jan; $7(1): 40-4$

12 Kaltofen T, Haase M, Thome UH, Laube M. Male sex is associated with a reduced alveolar epithelial sodium transport. PLoS One. 2015; 10(8): $\mathrm{e} 0136178$.

13 Mansson J, Fellman V, Stjernqvist K. Extremely preterm birth affects boys more and socio-economic and neonatal variables pose sex-specific risks. Acta pædiatr. 2015 May; 104(5):514-21.

14 Ito M, Tamura M, Namba F. Role of sex in morbidity and mortality of very premature neonates. Pediatr int. 2017 Aug;59(8):898905.

15 Roll C, Kutz P, Bührer C. Sex-specific actions of drugs in preterm infants. Acta Paediatr. 2019 Mar;108(3):398-400.
16 Voigt M, Fusch C, Olbertz D, Hartmann K, Rochow N, Renken C, et al. Analysis of the neonatal collective in the Federal Republic of Germany 12th report: presentation of detailed percentiles for the body measurement of newborns. Geburtsh Frauenheilk. 2006 10/01;66:956-70.

17 Poets C, Wiechers C, Rüdiger M. Optimale entlassung sehr unreifer Frühgeborener: Aktuelle Evidenz und eigenes Vorgehen. Monatsschr Kinderheilk. 2019;167:26-33.

18 R Core Team. R: A language and environment for statistical computing. Vienna, Austria: Foundation for Statistical Computing; 2020.

19 Zhao D, Zou L, Lei X, Zhang Y. Gender differences in infant mortality and neonatal morbidity in mixed-gender twins. Sci Rep. 2017 Aug 18;7(1):8736.

20 Roberts D, Dalziel S. Antenatal corticosteroids for accelerating fetal lung maturation for women at risk of preterm birth. Cochrane Database Syst Rev. 2006 Jul 19(3):CD004454.

21 Rojas-Reyes MX, Morley CJ, Soll R. Prophylactic versus selective use of surfactant in preventing morbidity and mortality in preterm infants. Cochrane Database Syst Rev. 2012 Mar 14(3):CD000510.

22 Horbar JD, Badger GJ, Carpenter JH, Fanaroff AA, Kilpatrick S, Lacorte $M$, et al. Trends in mortality and morbidity for very low birth weight infants, 1991-1999. Pediatrics. 2002;110(1 Pt 1):143-51.

23 Kusuda S, Fujimura M, Uchiyama A, Totsu S, Matsunami K. Trends in morbidity and mortality among very-low-birth-weight infants from 2003 to 2008 in Japan. Pediatr Res. 2012; 72(5):531-8.

24 Liang FW, Chou HC, Chiou ST, Chen LH, Wu MH, Lue HC, et al. Trends in birth weight-specific and -adjusted infant mortality rates in Taiwan between 2004 and 2011. Pediatr Neonatol. 2018 Jun;59(3):267-73.

25 Mehler K, Oberthuer A, Keller T, Becker I, Valter M, Roth B, et al. Survival among infants born at 22 or 23 weeks' gestation following active prenatal and postnatal care. JAMA Pediatr. 2016 Jul 1;170(7):671-7.

26 Benzies KM, Aziz K, Shah V, Faris P, Isaranuwatchai W, Scotland J, et al. Effectiveness of Alberta family integrated care on infant length of stay in level II neonatal intensive care units: a cluster randomized controlled trial. BMC Pediatr. 2020 Nov 28;20(1):535.

27 Moore ER, Bergman N, Anderson GC, Medley N. Early skin-to-skin contact for mothers and their healthy newborn infants. Cochrane Database Syst Rev. 2016 Nov 25;11(11): CD003519.

28 Sun J, Marwah G, Westgarth M, Buys N, Ellwood D, Gray PH. Effects of probiotics on necrotizing enterocolitis, sepsis, intraventricular hemorrhage, mortality, length of hospital stay, and weight gain in very preterm infants: a meta-analysis. Adv Nutr. 2017 Sep;8(5): 749-63.

29 Sullivan S, Schanler RJ, Kim JH, Patel AL, Trawöger R, Kiechl-Kohlendorfer U, et al. An exclusively human milk-based diet is associated with a lower rate of necrotizing enterocolitis than a diet of human milk and bovine milk-based products. J Pediatr. 2010 Apr; 156(4):562-7.e1.

30 O'Connor DL, Gibbins S, Kiss A, Bando N, Brennan-Donnan J, Ng E, et al. Effect of supplemental donor human milk compared with preterm formula on neurodevelopment of very low-birth-weight infants at 18 months: a randomized clinical trial. JAMA. 2016 Nov 8 ; 316(18):1897-905.

31 Blondel B, Kogan MD, Alexander GR, Dattani N, Kramer MS, Macfarlane A, et al. The impact of the increasing number of multiple births on the rates of preterm birth and low birthweight: an international study. Am J Public Health. 2002;92(8):1323-30.

32 Kulkarni AD, Jamieson DJ, Jones HW Jr, Kissin DM, Gallo MF, Macaluso M, et al. Fertility treatments and multiple births in the United States. N Engl J Med. 2014;370(11):106971.

33 Heino A, Gissler M, Hindori-Mohangoo AD, Blondel B, Klungsøyr K, Verdenik I, et al. Variations in multiple birth rates and impact on perinatal outcomes in Europe. PLoS One. 2016;11(3): $\mathrm{e} 0149252$.

34 Hinchliffe SR, Seaton SE, Lambert PC, Draper ES, Field DJ, Manktelow BN. Modelling time to death or discharge in neonatal care: an application of competing risks. Paediatr Perinat Epidemiol. 2013 Jul;27(4):426-33. 